\title{
VIDA COTIDIANA: USO/OCUPACIÓN DEL TIEMPO/ESPACIO Y RECONFIGURACIÓN identitaria de GÉnero en SAn Cristóbal de Las Casas, Chiapas
}

\author{
Daily Life: Use/Occupation of Time/Space and Gender Identity Reconfiguration \\ in San Cristobal de Las Casas, Chiapas \\ Guadalupe Cantoral-Cantoral
}

Resumen: El propósito de este trabajo es mostrar la importancia de estudiar la vida cotidiana para acceder al proceso de reconfiguración de la identidad de género de hombres y mujeres de la ciudad de San Cristóbal de Las Casas, incluido el papel del lenguaje y de la memoria en este proceso. La metodología utilizada se sustenta en argumentos teóricos constructivistas, cuyo corte cualitativo orientó el uso de entrevistas e historias de vida como técnicas privilegiadas. Los resultados muestran el contexto de la vida cotidiana como espacio donde se crean y recrean experiencias de desigualdad que constantemente trastocan elementos identitarios de género y donde hombres y mujeres realizan procesos de cambio en la reconfiguración identitaria y de condiciones de vida.

Palabras clave: vida cotidiana, identidad de género, memoria y lenguaje.

Abstract: The purpose of this paper is to show the importance of studying everyday life of men and women in the city of San Cristobal de Las Casas as a way to understand the process of reconfiguration of gender identity. Language use and memory are important elements in this process. The methodology used in the research is based on constructivist theory. Interviews and life stories were collected to give a qualitative assessment of change. We conclude that gender identity is in constant flux, influenced by life experiences that disrupt prior ideas and which lead to others based on more equality. In this context, men and women perform the search processes of change in the identity reconfiguration and conditions life.

Keywords: everyday life, gender identity, memory and language.

Guadalupe Cantoral Cantoral, doctoraen Ciencias Socialesy Humanísticas por el Centro de Estudios Superiores de México y Centroamérica de la Universidad de Ciencias y Artes de Chiapas, México. Coordinadora del posgrado en Estudios e Intervención Feministas del Centro de Estudios Superiores de México y Centroamérica de la Universidad de Ciencias y Artes de Chiapas, México. Temas de especialización: género, identidades, vida cotidiana y malestares. Correo electrónico: gcantoral2@live.com.mx.
Enviado a dictamen: 25 de junio de 2015 Aprobación: 15 de enero de 2016. Revisiones: 1. 


\section{Introducción}

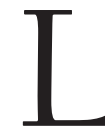
a sociedad mexicana ha experimentado transformaciones económicas, políticas, sociales y culturales que han impactado en la reconfiguración de las identidades de género. En las décadas de los sesenta y setenta se consolidó el crecimiento económico, incrementó la fuerza de trabajo asalariada, aumentó la migración del campo a la ciudad y crecieron las principales urbes del país, a la vez que se presentaron avances importantes en los ámbitos de la salud, la educación y la seguridad social (CEPAL, 1993). Otro aspecto importante fueron las transformaciones ocurridas en el marco de la globalización, que acarrean consecuencias en cuanto al trabajo y al empleo de la población.

En este contexto de cambio, las tendencias demográficas han jugado un papel fundamental en la vida social: descenso de la mortalidad a partir de 1930, aumento de la esperanza de vida y disminución de la fecundidad favorecida por el aumento del uso de métodos anticonceptivos - principalmente en espacios urbanos-, todo ello aunado al cambio en los patrones de nupcialidad, al aumento de la disolución de las parejas, al uso de nuevas pautas reproductivas y al incremento de mujeres en ámbitos extradomésticos, como la escuela y el trabajo (Echarri, 2010).

Estos factores han contribuido a conformar nuevos escenarios sociales, y el espacio familiar se ha transformado en tamaño, estructura y composición, con estilos diversos de organización y convivencia, proceso que modifica o cuestiona las definiciones y percepciones de la familia y, de manera particular, las actividades que realizan varones y mujeres.

No obstante, hay que considerar que no todas las familias en México se han visto alteradas por las transformaciones ocurridas, e incluso aquellas que han experimentado cambios, algunos de los cuales pueden pasar desapercibidos, no presentan características homogéneas; lo más común es que se observen transformaciones en algunos aspectos de las familias, mientras que en otros se perciban continuidades. De esta manera, los cambios pueden adoptar distintas definiciones por el grado de intensidad y la dirección que toman, pero a su vez varían en los distintos sectores y grupos sociales (Esteinou, 2004). En comparación con el contexto rural, en el urbano son más evidentes los cambios mencionados, de ahí que este espacio social sea cada vez más complejo y se encuentre enmarcado por contradicciones y ambivalencias en el ser/hacer de varones y mujeres.

En el caso específico de la ciudad de San Cristóbal de Las Casas, en Chiapas, México, se han presenciado cambios sustanciales en el acontecer cotidiano que tienen correspondencia con los ocurridos a nivel nacional señalados en párrafos anteriores. Con el acelerado crecimiento poblacional a partir de 1970, asociado con la migración masiva de indígenas de la zona Altos expulsados por conflictos religiosos (Robledo, 2010) y de población campesina hacia San Cristóbal de Las Casas (Villafuerte y García, 2006), ${ }^{2}$ el espacio social de esta ciudad presenta un mosaico cultural que trasciende la experiencia cotidiana de sus habitantes.

Asimismo, los factores económicos y políticos han incidido en la participación laboral de las mujeres, que ha aumentado por sus intereses personales y, en cierta medida, por el ejercicio de un derecho que se empezó a reivindicar con el movimiento feminista de 1970. La vivencia subjetiva del trabajo formal conduce, para muchas mujeres, a beneficios personales de índole psicológica, afectiva y emocional, de modo que éste se advierte como importante en su reconfiguración identitaria. Asimismo, la reducción del número de hijos ha desempeñado un papel fundamental en la posibilidad de que más mujeres se desenvuelvan en un trabajo formal, ya que ha contribuido a que dediquen más tiempo a otras actividades -educativas, laborales o comunitarias-, así como a proyectos personales. ${ }^{3}$

El panorama de las identidades de género en México, y en el caso particular de San Cristóbal de Las Casas, se encuentra en una encrucijada con muchas complicaciones; varones y mujeres nos enfrentamos a discursos de igualdad de género que siguen conviviendo con discursos y prácticas cotidianas caracterizados por 
la desigualdad. Desde su fundación en 1528, la ciudad se ha caracterizado por ser un espacio de encuentro y desencuentro de personas de diferentes lugares de origen, lo que la ha convertido en un mosaico de lenguas, costumbres, vestimentas, formas e ideologías de vida y, en los últimos años, de creencias religiosas.

En la sociedad sancristobalense se pueden encontrar particularidades que marcan diferencias socioculturales entre sus pobladores y que inciden en la vida práctica y subjetiva, pero a nivel colectivo se comparten rasgos e intereses comunes que se cohesionan a través de la edificación de representaciones llenas de simbolismo (Cancino, 2007). A la par, la situación política, económica, educativa y laboral de la entidad chiapaneca posee sus propias complejidades, lo cual ha impactado en la vida cotidiana de varones y mujeres.

La vida cotidiana o cotidianidad es el espacio en el que los individuos nos confrontamos con la propia identidad de género y con discursos o prácticas provenientes del contexto social que, o bien refuerzan los elementos constitutivos de nuestra identidad, o nos ponen en franco cuestionamiento con nosotros mismos y con la alteridad.

En el presente documento se apunta la importancia de la vida cotidiana como espacio donde se reconfiguran elementos de la identidad de género de varones y mujeres, cuyo énfasis en el discurso y en la memoria responde a la importancia de éstos en el proceso de cambio de sentidos y significados que la acompañan. De esta manera, en el primer apartado se presentan los planteamientos desde los cuales entiendo y abordo la vida cotidiana, para profundizar en el segundo apartado en el papel del lenguaje y la memoria como parte de este proceso de cambio.

Los datos empíricos corresponden a un estudio más amplio que realicé desde una perspectiva constructivista y de corte cualitativo, y se centra en las historias de vida realizadas a seis mujeres y tres varones de entre 30 y 40 años de edad que vivían en pareja y con hijos e hijas al momento del estudio. ${ }^{4}$ Las entrevistas a profundidad se realizaron a cinco varones y cinco mujeres mayores de 50 años. Todas las personas que participaron son originarias de la ciudad de San Cristóbal. ${ }^{5}$

\section{Algunas puntualizaciones sobre la vida cotidiana}

La vida cotidiana transcurre en un espacio social cuya reorganización es definida por sus habitantes y sus particularidades de vida, sin por ello ser ajena a la situación política, económica y cultural del contexto, es decir, del espacio de interacción en el que discurre la vida diaria de varones y mujeres. En el caso de esta investigación, el espacio social es la ciudad de San Cristóbal de Las Casas, en Chiapas, México, donde se han experimentado transformaciones que comprometen la cotidianidad de la vida en pareja, las relaciones de género y las subjetividades.

En el transcurso de la segunda mitad del siglo XX, la sociedad sancristobalense se abrió a personas y oportunidades diversas, cambió la imagen de las mujeres respecto a permanecer dentro de casa y empezó a aumentar su inserción escolar ${ }^{6}$ y laboral. ${ }^{7}$ Un cambio en la organización familiar del trabajo ha sido el paso del trabajo remunerado en el interior de la casa —elaboración y venta de tamales, elaboración de dulces, entre otrasal trabajo fuera de ella - empleadas, comerciantes, entre otras-. Las vías y medios de comunicación tuvieron un papel central al generar un efecto profundo en la conducta de las mujeres, así como en su participación política, profesional o en grupos de ayuda.

Respecto al ámbito político, es importante mencionar que las mujeres en Chiapas tuvieron derecho al voto cuando éste se estableció constitucionalmente el ll de mayo de 1925 mediante un decreto que les confería derechos de ciudadanía y las declaraba jurídicamente iguales a los varones, acontecimiento histórico que se presentó veintiocho años antes a lo dispuesto por la federación para el ámbito nacional. A partir de entonces, en el territorio de Chiapas a las mujeres mayores de dieciocho años se les reconocen los mismos derechos políticos que a los varones, y tienen derecho a votar y a postularse para cargos públicos, lo que no necesariamente significa que la participación política de las mujeres sea válida y reconocida socialmente.

Aunque en las luchas sociales de Chiapas las mujeres han tenido una participación activa, ésta ha sido prácticamente invisible. La rígida división 
sexual del trabajo sólo hasta muy recientemente ha permitido una participación amplia y pública de las mujeres en las luchas populares, aunque siempre han estado encabezadas por varones, como es el caso del movimiento campesino de mediados de los setenta $\mathrm{y}$ fines de los ochenta del siglo XX, que dio como resultado la Reforma Agraria del estado. Las mujeres también participaron, en los ochenta de ese mismo siglo, en las movilizaciones de promotores y maestros indígenas que buscaban la homologación de sus plazas con las de los maestros federales (Olivera, 2009). En esa misma década coincidió en Chiapas el desarrollo de diferentes movimientos y conflictos sociales: luchas campesinas, importantes movilizaciones del magisterio, conflictos religiosos y la expulsión de numerosas familias de varios municipios de la región Altos de la entidad. Hubo también movimientos migratorios que modificaron la composición demográfica, el uso de la tierra, la estructura económica y las relaciones sociales del estado (Garza y Toledo, 2004).

En este contexto, la ciudad, al ser receptora de migrantes de otras latitudes, se convirtió en un espacio con presencia habitual de conflictos y fricciones en la vida social, más cuando en ella habitan familias desde hace generaciones que no en raras ocasiones se sienten dueñas de San Cristóbal. La ciudad pequeña y tranquila recordada por muchos de sus habitantes ha dejado de serlo, porque en ella habitan cada vez más personas a quienes "ya no se les conoce".

Siguiendo los planteamientos de Berger y Luckman (2005), la vida cotidiana se presenta para los individuos como una realidad coherente por los significados subjetivos con que se interpreta, y por ser el mundo a partir del cual se originan pensamientos y acciones considerados como reales. La vida cotidiana es un mundo intersubjetivo, es decir, se comparte con otras personas en una correspondencia de significados que permite la interacción. Estos significados socialmente compartidos se van configurando en el transcurso de la vida por los procesos biográficos, en los que se incorporan elementos del conocimiento compartido y las objetivaciones que ocurren con la sedimentación de la experiencia, lo que conforma el propio acervo subjetivo de conocimiento y hace asequible la comprensión de la alteridad (Lindón, 2000).

La subjetividad, explica Alcoff (1989), como producto emergente de la experiencia, surge como resultado de la experiencia de interacción y del compromiso individual con las prácticas, los discursos y las instituciones que otorgan significado a los acontecimientos del mundo y, como resultado de la experiencia, se encuentra en constante renovación. En este sentido, los espacios sociales cambiantes significan reconfiguraciones subjetivas que no sólo hacen posible la existencia del sentido y significado de la cotidianidad vivenciada, sino también la reconfiguración identitaria de género.

En el proceso de configuración de la identidad genérica, entendida con base en planteamientos de la perspectiva de género constructivista, a mujeres y varones se nos educa de manera diferencial, lo cual lleva a construcciones de lo femenino y de lo masculino y nos ubica en relaciones y posiciones de género. A partir de estas prácticas, varones y mujeres nos comprometemos con esa posición de género y experimentamos los efectos de estas prácticas en la experiencia corporal, en la personalidad y en la cultura (Connell, 1997).

La identidad de género recreada en la práctica cotidiana otorga coherencia a la existencia y establece un puente entre la experiencia individual y la vida social. Asimismo, se conforma por una variedad de discursos que son utilizados para dar sentido a nuestras acciones en los diferentes ámbitos en que se desenvuelve nuestra vida diaria. Ante experiencias sociales en constante cambio, los discursos pueden mostrarse diferentes, e incluso contradictorios, de manera que los discursos aprendidos y reproducidos constantemente en la cotidianidad dificultan la construcción de sentido de las nuevas prácticas de género.

Las actividades diferenciadas por género, como uno de los elementos constitutivos de la identidad de género, se encuentran fuertemente relacionadas con los espacios que habrán de ocupar varones y mujeres e implican diferenciaciones respecto al "deber ser/ hacer". Esta diferenciación es una constante en la cotidianidad relatada por mujeres de San Cristóbal 
que viven en pareja, ${ }^{8}$ como ejemplifican los relatos de algunas mujeres:

[...] la realidad es otra totalmente, porque vengo, me caso, bueno: "a ver, a ver, estás de vacaciones, levanta la casa, haz esto, haz lo otro" [decía él]. Y yo le decía: "ióyeme!, estoy de vacaciones, pero ayúdame". O él estaba desempleado casi un año y yo le decía, "ayúdame", que no hacía nada, "empleado o desempleado no ayudas y así no es un matrimonio. Si nos casamos es para estar juntos en las buenas y en las malas, no únicamente en las buenas" (Mary, 30 años). ${ }^{9}$

Ser más, no sé, [...] más aventado, que no tuviera miedo, que tuviera más ganas, no temeroso, me gustaría que ganara más. Yo también he tenido la idea de no trabajar tiempo completo para cuidar a mis hijas, para que no estén sin mí. También quiero que su papá esté con ellas, pero en realidad yo le pongo más peso a mi compañía que a la de él, sí. Yo he querido no trabajar mucho más por eso, para estar un tiempo con ellas, porque necesitan que la tarea, otras actividades por la tarde, cosas que hay que ver y estar. Si yo voy a hacer eso, él tiene opción de trabajar más por la tarde, y si alguien no le ofrece algo, no trabaja, no lo hace [...] sí tiene que ver con el concepto de que, si es hombre, que trabaje más, como yo soy mujer, también trabajo, pero también voy a ver a las hijas (Mary, 30 años)

Aunque los límites espaciales en las actividades laborales y domésticas de varones y mujeres son menos rígidos debido a los cambios ocurridos por la inserción educativa y laboral de las mujeres, y estas actividades son "compartidas" por ambos sexos - no necesariamente en igualdad-, se han hecho necesarias nuevas formas de reorganización de la familia y de interacción entre sus miembros. Además de ello, son comunes los casos de mujeres que no se incorporan al trabajo formal porque el esposo no se lo permite, lo que las ubica en situaciones de desigualdad, al verse impedidas para ejercer su derecho al trabajo formal y para acceder a recursos económicos, como señala una de las encuestadas: "Él no quiere que trabaje, cosa fea" (Martha, 34 años)
Quien mira de forma detallada las calles de San Cristóbal, puede darse cuenta de que la división sexual de los espacios compromete la vida cotidiana, en tanto que se llevan a cabo infinidad de actividades permeadas por esta diferenciación: albañiles, vendedoras ambulantes de pastelitos, varones en el transporte público, mayoría de mujeres yendo a dejar y a recoger a sus hijos a la escuela, entre otras. Si nos detenemos a escuchar, es posible acceder a la vivencia del transcurrir cotidiano de varones y mujeres, lo que nos proporciona elementos para la comprensión: mujeres en la queja cotidiana de la multiplicidad de actividades por hacer en el día y el poco tiempo para realizarlas, varones hablando de las precarias condiciones laborales y mujeres platicando de sus hijos, son todas situaciones cotidianas de desigualdad.

El acontecer cotidiano se encuentra organizado por un tejido de tiempos y espacios que garantiza la reproducción del "orden social" construido y dinamizado principalmente en los contextos urbanos. Las múltiples actividades que hay que realizar en el día a día, aunadas a los tiempos para realizarlas, implican el "uso adecuado del tiempo" que pareciera administrar la vida cotidiana.

La interacción cara a cara es el prototipo de la interacción social. En ésta, el alter aparece en un presente vivido caracterizado por el constante intercambio de expresividades. Sin ser la única forma de interacción social, sobre todo si pensamos en el avance tecnológico y en las formas diversas de interacción a las que ha dado lugar, en las situaciones cara a cara se adquiere la experiencia más significativa de los otros. En estas interacciones, los otros son aprehendidos y tratados con base en múltiples elementos tipificadores, ${ }^{10}$ contenidos en la realidad de la vida cotidiana, que afectan la interacción con la alteridad. Algunas de estas tipificaciones son las normas de género." Las tipificaciones funcionan como bases cognitivas normadas socialmente que simplifican las interacciones y, a su vez, de acuerdo con el contexto de la interacción, limitan el proceso de conocimiento o comprensión del otro.

Asimismo, en el espacio de la vida cotidiana se pueden observar los cambios ocurridos en la distribución 
de actividades, los cuales no son insignificantes, son cotidianos y por ello pueden pasar desapercibidos: aumento de mujeres en el ámbito público - escolar y laboral - e incremento - aunque mínimo - de la participación de los varones en el cuidado y atención de hijos e hijas, así como en las actividades de la casa. Estos cambios se observan con mayor claridad entre las personas entrevistadas que vivían una relación de pareja en la que ambos miembros tenían un trabajo formal, lo que les implicaba reorganizaciones familiares para cumplir con las actividades remuneradas y las actividades domésticas.

Los cambios ocurridos y observados en la cotidianidad implican que varones y mujeres se confronten con nuevas problemáticas, relacionadas éstas con la demostración de habilidades, aptitudes y capacidades que precisan los nuevos espacios en que se desarrolla su cotidianidad, y con la interpretación que se realiza de las mismas. En este sentido, es importante señalar lo planteado por Cazés:

[...] la asignación de género y, por lo tanto, la definición de los tiempos masculinos y femeninos, es apenas el comienzo de un proceso siempre inconcluso de especialización. En él, cada individuo limita sus posibilidades de vida a la realización exclusiva de ciertas actividades, míticamente agrupada en productivas y reproductivas, a la percepción de la realidad desde perspectivas excluyentes, a formas de ser, de pensar y de sentir restringidas por sistemas intelectuales y efectivos segregados, a la integración diferencial en mundos - tiempos y espaciospropios, en círculos obligatorios o vedados, para incidir en ellos (Cazés, 2006: 71).

Los espacios público y privado que son construidos y significados por los sujetos también construyen sujetos, y las rupturas espaciales requieren de la emergencia de construir nuevos referentes identitarios para resignificar las identidades de género y procurar otros sentidos subjetivamente significativos de la práctica cotidiana propia y de los otros. El proceso de resignificación se realiza siempre en relación con las alteridades, nunca en su ausencia. Los relatos de Pepe y Elisa muestran un poco este entramado conflictivo:

[...] me siento mal que alguien me diga que soy buen padre. No es que alguien me haya dicho ser buen padre es así, podría ser una parte de lo que yo hubiese querido que mi papá fuera conmigo, no digo que mi papá haya sido fatal, pero sí me hubiera gustado que se involucrará conmigo, jugara conmigo, platicara conmigo, estuviera pendiente de mis tareas, de yo tenerle confianza. En parte es eso, que encuentren en mí a un amigo, ser un papá estricto pero que confíen en mí, no es darles toda la libertad, que no me vean como un ogro. Por otro lado, quizás tenga que ver con mi hermano, ${ }^{12}$ porque así me imaginaba que él iba a ser; podría ser, pero menos. Tal vez se fue dando de esta manera, como el querer reponer tiempo, no estaba en la semana y el fin de semana quería reponer tiempo y lo acaparaba, y eso me fue metiendo en ese papel con mis hijos e incluso a ella [su esposa] la descuidaba (Pepe, 30 años).

Cuando me fui a trabajar, los niños se apegaron a él. Yo me iba todo el día y me sentía a un lado. Pasaron los años y fue igual, y yo dije "no". Algo en mí, yo ya no quería hijos y de nuevo me vino el sentimiento de querer embarazarme porque veía que mis hijos estaban muy apegados a él, y decía "me voy a quedar sola, ellos se van a ir con él". Y se me metieron esas ideas en la cabeza y decidí embarazarme. Fue una decisión personal tener el tercer bebé [...] yo le decía a mi mamá: "este bebé va a ser sólo mío, mío" (Elisa, 38 años).

Es importante aclarar que el espacio es construido física y subjetivamente, es decir, lo que se hace en los espacios otorga sentido a la existencia y, cuando las actividades se modifican, el espacio requiere de resignificaciones que otorguen sentido a quienes interactúan en él en la vida diaria.

Pensar la vida cotidiana regularmente en términos de actividades repetitivas hace que ésta se muestre 
con naturalidad. Las rutinas obedecen a factores institucionales y a formas creadas por lo vivido que cada quien construye, y otorgan cierto grado de seguridad, liberan del peso de las decisiones permanentes y evitan la angustia diaria de organizar tiempos y espacios, porque cada vez es más necesario ganar tiempo ante el ritmo que impone la vida urbana. Por otra parte, las actividades domésticas que realizan las mujeres diariamente provocan cansancio y aburrimiento, por lo que ellas intentan romper la monotonía a través de: fiestas, reuniones con amigas, reuniones familiares, rezos, eventos escolares de los hijos e hijas o eventos religiosos, lo que en ocasiones conduce a sanciones por parte del esposo, como relata Pili:

[...] no tiene nada de malo que me vaya a comer y me tome una mi cervecita, tengo derecho a divertirme sanamente [...] Mi hija se enoja conmigo, pero no lo hago todos los días. Cuando mi esposo llegó del trabajo, se quejó con él porque se quedó a cargo de su hermanita [6 años] y él me regañó. La verdad, sí me sentí mal (Pili, 38 años).

Un mecanismo de ruptura de la cotidianidad que eligen los varones jóvenes entrevistados es la práctica del futbol; incluso la rutina de jugar todos los domingos, como en el caso de Alejandro (33 años), es para él una vía para romper con otras rutinas, la del trabajo y la de la vida familiar, lo cual también tiene costos en la relación de pareja por las constantes discusiones que mantienen porque él elige jugar y no estar con ellas - esposa e hija, principalmente- - A diferencia de las mujeres, aunque los varones tengan conflictos con su pareja por ir a jugar futbol, jamás señalaron que se sentían "regañados" por las mujeres, lo cual indica la situación de subordinación en la que ellas se encuentran con respecto a sus esposos, aunado al hecho de que las mujeres tienen menos tiempo y posibilidades de romper con la rutina dadas sus múltiples responsabilidades domésticas, que continúan incluso los fines de semana.

Aunque en la vida cotidiana se encuentra una de las fuentes de innovación social en la que debe tenerse en cuenta su historicidad, las rutinas repetidas diariamente son a su vez "necesarias" porque permiten ganar tiempo y dan tranquilidad, pero simultáneamente son "pesadas" porque el "ser" no se puede reducir a una vida monótona y sin reacción. Esto se observa claramente cuando las mujeres y hombres entrevistados explicaron la organización con la pareja o las redes de apoyo para cubrir con las responsabilidades cotidianas, tales como: ir a dejar y a traer a los hijos e hijas a la escuela, preparar el desayuno y la comida, cuidar y atender a los hijos o realizar las labores domésticas.

Los argumentos mencionados permiten deducir que la vida cotidiana es simultáneamente habilitante y constrictiva (Reguillo, 2000); sin embargo, es en este espacio donde se pueden llevar a cabo rupturas y posteriores transformaciones.

\section{Ruptura de la cotidianidad como espacio de posibilidad}

Una forma de entender la ruptura de la cotidianidad se puede recuperar de los planteamientos de Reguillo (2000). Para esta autora, los sujetos nos movemos en la vida cotidiana con base en presupuestos pragmáticos que funcionan como elementos orientadores de la acción colectiva. Esto no significa que nos apropiemos de los presupuestos sin mayor inconveniente, sino que también se producen resistencias, negociaciones y oposiciones ante aquello que aparece como "normal" o "natural", que quedan desmanteladas cuando surgen otros presupuestos pragmáticos que ponen en cuestión las "certezas" o "verdades" construidas por los sujetos. El caso de Rosa ejemplifica este conflicto en el tema específico de la maternidad:

Yo no quiero ser la mujer abnegada que ahí está y que da su vida por sus hijos, porque no, yo no quiero eso ni estoy de acuerdo. Por otra parte está la mujer que ve por su propia vida, por sus propios intereses, que trabaja y no está totalmente entregada [...] yo sentía que era así, que era incongruente [...] ahora soy más pasiva, más tolerante, menos estricta, no pasa nada si soy mamá tradicional, si soy de casa, está bien, si lo necesitan $[. .$.$] pensaba que a mis hijas les hace sentir$ 
bien eso, que mamá está ahí, está dispuesta, está para ellas, con medida también, no tanto. Empecé a dudar de lo que pensaba, de qué tan cierto era que sí va más allá del concepto, y es como natural o instintivo que mamá tenga que estar como con los animalitos y que mamá tiene que estar hasta que crezcan y el tiempo que necesite cada especie, y decía: “iserá que me estoy yendo contra lo natural?” Eso, ahí empezó un poco y me ha costado marcar (Rosa, 36 años).

Desde lo planteado por Reguillo, el elemento fundamental para entender el cambio surge de la diversidad de sujetos portadores de discursos que coexisten en la cotidianidad y otorgan sentidos diversos a sus prácticas cotidianas, de manera que terminan relativizando lo "verdadero". Si la vida cotidiana es construida y significada con la alteridad, que la convierte en un mundo intersubjetivo, se requiere de un discurso que la haga explícita y proporcione elementos que la fundamentan. Los discursos son objetivaciones cuyo repertorio más o menos duradero se encuentra cargado de procesos subjetivos de quienes lo producen, y su disponibilidad se extiende más allá de las interacciones cara a cara.

Aunque los discursos como sistemas de signos no son las únicas objetivaciones que se encuentran en la realidad cotidiana, poseen vital importancia por su intención explícita de ofrecer otras señas contenidas de significados subjetivos y por su capacidad de desprenderse del aquí y el ahora inmediatos en los estados subjetivos (Berger y Luckman, 2005).

Es importante señalar que la oración es la unidad básica del discurso y ésta, a su vez, se define como la unidad de significación más pequeña del lenguaje organizada gramaticalmente (Ribeiro, 1989). Mendoza señala que: "el lenguaje es un acuerdo social sobre la realidad, sobre cómo designarla, y dentro de éste se da la comprensión y la inteligibilidad del mundo, pero sobre la base de acuerdos colectivos" (2005: 7). Lo relatado por Mary muestra la importancia de los discursos legitimados socialmente respecto al deber/hacer de un esposo y el conflicto que implica en la vida cotidiana: "Dios mío, éste no es un matrimonio, ahora sí que yo la estoy haciendo de hombre, y esos eran los problemas fuertes que teníamos y yo le decía: 'acuérdate de lo que dijo el padre, que tú como hombre tienes que dar la cara y me tienes que ayudar"' (Mary, 30 años).

Cabe aclarar, sin afán de profundizar, que el discurso es un conjunto de enunciados - realización de la lengua- encaminados a un solo fin expresivo que se denomina prácticas discursivas. Cada práctica discursiva se encuentra en correspondencia con la tradición, tanto lingüística como fáctica, que moldea las características en que se presenta el discurso en los diferentes hablantes. Los hablantes son un conjunto de personas unidas por una práctica determinada que les condiciona y les otorga identidad como comunidad, y tienen un repertorio común de comunicación y entendimiento, entre otras cosas (Ribeiro, 1989).

En este sentido, el lenguaje es esencial para la comprensión de la realidad de la vida cotidiana y, por su capacidad de trascender la inmediatez —en sus dimensiones espacial, temporal y social-, establece puentes entre diferentes aspectos de la realidad cotidiana para integrarlos en un todo significativo. Aunque los conocimientos socialmente compartidos son posibles por el lenguaje, debe tenerse en cuenta que la vida cotidiana se ordena en términos de lo que nos es más relevante o apremiante, ya sea por intereses pragmáticos inmediatos o por la propia situación general en la que la persona se encuentra en la sociedad.

El discurso social que construye la narrativa o discurso individual a través de la experiencia vivida, en diálogo con ideologías sociales, juega un papel fundamental en la reconfiguración de la identidad. La naturaleza simbólica del lenguaje permite interpretar lo que somos y tener una determinada imagen propia - autopercepción- y de los otros que puede ser comunicable en el contexto social. Esta representación se convierte en una subjetividad comunicable marcada por los procesos sociales que la generan, y por su carácter simbólico contiene valores y creencias que se han incorporado en la autodefinición. "Es en este sentido que se afirma que somos y actuamos de acuerdo con aquello que narramos sobre nosotros mismos, y eso 
más que de acuerdo con una hipotética determinación natural u objetiva" (Íñiguez, 2001: 6). Cuando los discursos cambian es porque quienes los producen también son distintos, en eso radica su historicidad y la subjetividad que media entre discurso y sujetos (Riquer, 1997).

Los discursos acerca de la identidad y de las relaciones de género son, además de conocimiento acumulado por las culturas, mensajes que circulan en el contexto sociocultural transmitidos como verdades, que al ser internalizados por los sujetos funcionan como base para interpretar acciones, pensamientos y sentimientos, propios y de otras personas, en conformidad con los discursos sociales (Fuller, 1997). No obstante, en un contexto en permanente cambio, los discursos que orientan a los sujetos en sus prácticas cotidianas se debilitan en su función cohesionadora, y los postulados socioculturales comprensibles cognitiva y lingüísticamente por los sujetos buscan ser restituidos a través de la intersubjetividad que garantice la continuidad del grupo social.

En esta búsqueda de restitución de postulados, Reguillo (2000) reconoce dos tendencias: por un lado se encuentra la reemergencia de discursos totalitarios o intolerantes que interpelan la subjetividad mediante argumentos centrados en la recuperación de lo perdido: las costumbres, la centralidad de la familia, los valores religiosos o el exacerbamiento de los nacionalismos. Esta perspectiva es cerrada y excluyente con la finalidad de conservar y seguir reproduciendo dispositivos de continuidad. Este tipo de discurso se presenta más entre las generaciones mayores, como se muestra en el siguiente relato:

La obligación de la mamá [con los hijos] es educarlos, enseñar buenos principios, cumplir con ellos, asearlos, todo lo que le corresponde a una mamá responsable; lo da uno todo por los hijos. Estoy muy orgullosa de mis hijos, tienen otro tipo de vida gracias a que aprovecharon la oportunidad que les dimos de estudiar (doña Carol, 67 años).

La esposa se debe hacer cargo de la casa, que esté limpio, arreglado, la comida, la ropa, atender al esposo y a los hijos. El esposo debe ser responsable, llevar el gasto a la esposa para la comida, no maltratarla, cuidarla, atenderla si está enferma. Yo le doy el gasto a mi esposa. Hasta la fecha sigo trabajando para que a ella no le falte la comida. Si no doy gasto, icómo puedo llegar a sentarme a la mesa para que me sirvan? Nooo. En cambio, así sé que me van a servir mi comida porque doy el gasto (don Rolando, 68 años).

Por otro lado está la comunicación centrada en la selección de códigos que se fundamenta en una definición común de la situación y hace posible la emergencia de relaciones horizontales. Es decir, se trata de una comunicación que se articula a través de la interacción y no se centra en contenidos esenciales. No obstante, este tipo de discurso es casi nulo en los relatos de las personas entrevistadas, y los pocos que se identifican con él hacen alusión a ser más equitativos en las responsabilidades domésticas y en el cuidado y atención de hijos e hijas.

A estas dos tendencias me parece pertinente agregar una intermedia basada en lo que plantea De Certeau (2000). En ésta, los individuos "metaforizan el orden dominante" y lo hacen funcionar en otro registro. El lenguaje producido por una categoría social dominante dispone del poder de extenderse, privilegio que puede ser aparente si sólo sirve de marco a las prácticas de los sujetos que lo utilizan y manipulan en la cotidianidad. Dicha "metaforización", De Certeau la ubica en el contexto de la conquista española. ${ }^{13}$

La "metaforización del orden dominante" en las identidades de género se hace presente en las diferentes maneras de viviry practicar lafeminidadyla masculinidad; aunque se tengan como referentes normatividades de género, éstas no son incorporadas de manera absoluta por los sujetos. Al respecto, parafraseando a Giménez (2005), la identidad de género es posible a través de la alteridad y supone la existencia de características distintivas que definen la particularidad de una persona respecto de otras. Asimismo, posee características que le hacen semejante, es decir, es resultado de una "identificación contingente" ${ }^{14} \mathrm{y}$ se relaciona con un contexto cambiante cuyos elementos se entrelazan como una red: la situación 
económica, las instituciones y las ideologías, tanto políticas como culturales. Es en el contexto de las interacciones donde surge la manera subjetiva en que la identidad de género se representa.

En la práctica cotidiana las identidades se reconstruyen, resignifican y reelaboran dentro de ciertos parámetros en una especie de "subversión desde dentro", de lo que deriva la existencia de feminidades y masculinidades, en plural, y no en singular. De no ser así, habría dos grupos claramente definidos dentro de los contextos: mujeres y varones como esencias determinadas por las normas de género.

Como ejemplo de lo anterior me referiré al relato de vida de un varón respecto de las relaciones coitales con mujeres. Él recordó que durante el bachillerato se reunía un grupo de amigos para hablar de experiencias sexuales; como él no las tenía, para evitar la burla de sus compañeros recurría a la adulación y el fanfarroneo. El tema sexual no le preocupaba - sino hasta finales del bachillerato-, y para no enfrentarse con sus amigos por su "desinterés" sexual simulaba participar del mismo "juego" que ellos, de modo que evitaba la exclusión por no corresponder con el modelo hegemónico de la masculinidad, en el cual las experiencias coitales heterosexuales son símbolo de virilidad.

Estas tres tendencias del discurso como parte del proceso de restitución de postulados para resignificar o reorientar las prácticas cotidianas son estrategias que bien pueden ser utilizadas para resolver situaciones de crisis, conflictos, contradicciones o ambivalencias. El cambio al cual se orientan, en diálogo con discursos dominantes, no necesariamente conlleva igualdad y cambio social, pero puede incluir o generar estos elementos, excepto la primera tendencia, que se relaciona más con la "adaptación" en la que se favorece la continuidad de las normas de género.

Es claro entonces el papel del lenguaje como elemento fundamental en el proceso de cambio, principalmente en momentos de ruptura o crisis, pero iqué otro proceso favorece la puesta en cuestión de las certezas construidas socialmente, que una vez naturalizadas garantizan su reproducción social en la vida cotidiana?
El análisis se puede orientar partiendo de un proceso cognoscitivo que, al igual que el lenguaje, es construido socialmente: la memoria. Hablar de memoria lleva a retomar el tema del tiempo, que puede concebirse como lineal si se parte de que sucede cronológicamente, pero se complica cuando se introducen los procesos históricos y la subjetividad humana, como sucede en los relatos de vida, los cuales se van construyendo de acuerdo con la subjetividad de quien relata. Su significatividad está dada por elementos afectivos, más que por el seguimiento de una lógica en la cronología de los acontecimientos, porque la carga afectiva otorgada a las experiencias orienta el curso del relato. Al respecto, Halbwachs expone:

El tiempo no es real más que en la medida en que tiene un contenido, es decir, en que ofrece una materia de acontecimientos al pensamiento. Es limitado y relativo, pero tiene una realidad plena. Es lo bastante extenso para ofrecer a las conciencias individuales un cuadro suficientemente amplio para que puedan disponer de él y reencontrar sus recuerdos (Halbwachs, 1950: 129).

Mendoza (2005) señala que a la configuración de la memoria contribuyen los marcos sociales, tal como el tiempo - fechas - y el espacio - lugares - , que guardan eventos significativos para su posterior conmemoración y sobre los cuales las sociedades construyen sus recuerdos. El recuerdo es posible por el lenguaje en tanto que éste es una producción cultural; se recuerda por medio de construcciones sociales, y el lenguaje dentro de la colectividad es uno de ellos. "El lenguaje, como entidad que permanece, que tiene cierta fijeza, concede que los recuerdos fluyan por él, y aunque los recuerdos, es decir, el contenido se vaya, el marco fijo como es permanece" (Mendoza, 2005: 8).

El pasado se reconstruye y resignifica aun cuando lo sucedido sea imposible de cambiar; es decir, la lectura del pasado desde el presente permite dar otros sentidos y significados al recuerdo para incidir en el presente y las expectativas futuras. Esto requiere de "trabajos de memoria”, como los denomina Jelin (2002), y significa 
que los sujetos presentan una posición activa en el proceso de transformación simbólica y en la elaboración de los sentidos del pasado.

Los relatos de las personas entrevistadas apelan a los recuerdos que les han sido significativos y le otorgan sentido a la existencia en tanto seres sexuados. Para ellos, el ser/hacer como varones o mujeres presenta correspondencias con lo vivido en etapas anteriores de la vida. Por ejemplo, la vivencia del ser/hacer madre o padre cobraba sentido al compararla con su propia experiencia como hijas e hijos, y en dichos recuerdos el tiempo/espacio en que ocurrió fue fundamental en su configuración de la identidad de género. Ubicar a la madre o al padre en determinados lugares haciendo determinadas actividades, el maltrato, el contacto afectivo o el establecimiento de reglas, son todas experiencias que se sitúan en un tiempo y espacio específicos.

Los "trabajos de la memoria" ubicados desde un juicio crítico podrían contribuir a reelaborar y resignificar el pasado con la finalidad de procurar cambios en los sentidos identitarios y en las condiciones de la vida cotidiana, o a fortalecer argumentos orientados a la continuidad de normas de género caracterizadas por la desigualdad intergénero e intragénero: la "adaptación como solución”, como la he denominado.

Lo contrario es un presente penetrado por las vivencias del pasado expresadas como: huellas mnésicas, silencios, compulsiones o repeticiones en las que no media la voluntad, la conciencia o la estrategia de los sujetos, situaciones en las que no existen "trabajos de memoria". Jelin ve un doble riesgo: por un lado, un "exceso de pasado" expresado en la repetición ritualizada y, por otro, el olvido selectivo instrumentalizado y manipulado. Por eso considera que la única salida es la reelaboración de la memoria.

Si bien las experiencias incorporadas pueden permanecer debido a una memoria sedimentada, éstas pueden modificarse y el lenguaje puede ser utilizado como estrategia de resignificación del pasado y del presente mediante el uso de otros elementos argumentativos o al cambiar el sentido de éstos
(Jelin, 2002). En frases señaladas por algunas de las personas entrevistadas se identifica la resignificación que se realiza del pasado: "yo no quiero ser como mi papá", "no quiero ser la madre abnegada", "ni toda la responsabilidad para él ni toda la carga para mí", "quiero que mis hijos me tengan confianza, no quiero que me tengan miedo, ser un padre cariñoso", por mencionar algunas. En dichas frases los entrevistados han efectuado un proceso de reflexión para establecer relaciones distintas con los hijos e hijas y con la pareja; el proceso se encuentra en constante diálogo entre pasado y presente. Al respecto, Taracena (2012) señala que la reflexión retrospectiva permite recorrer distintos puntos de vista y compararlos, y desde ellos se sacan inferencias sobre lo sucedido en el tiempo y en el espacio.

No obstante, la resignificación del pasado habrá de realizarse con juicio crítico, porque de otra manera se puede "cambiar todo para no cambiar nada", como popularmente se dice; es decir, el cambio puede ser superficial o aparente, de modo que se siguen reproduciendo prácticas que favorecen las desigualdades intergénero e intragénero. Aunque el juicio crítico no garantiza la búsqueda de cambios hacia la igualdad, sí es un elemento necesario para procurarlo.

Es importante aclarar que el distanciamiento de las normatividades de género puede responder a dos situaciones diferentes: una de ellas ocurre cuando las condiciones cotidianas orientan u "obligan" a prácticas que distan de lo esperado socialmente o con la propia construcción de lo que varones y mujeres consideran su ser/hacer en tanto seres genéricos; la otra se relaciona con identidades que se han configurado desde otras experiencias que plantean formas alternas del ser/hacer.

La maternidad y la paternidad, relacionadas con la división sexual del trabajo, son temas de relevancia en la experiencia de las mujeres y los varones entrevistados porque constantemente se autocuestionan su ser/hacer con los hijos, reproduciendo y evitando normatividades de género. En todo este proceso, la inserción escolar y laboral de las mujeres ha sido fundamental no sólo 
para ellas, sino también para sus parejas; asimismo, la diversidad de discursos y prácticas que circulan en el contexto ponen en cuestión las verdades y certezas construidas.

A través del proceso de reelaboración de los recuerdos desde una práctica reflexiva y crítica, las resignificaciones y sentidos que los sujetos dan a sus experiencias pasadas generan condiciones para la producción de otros discursos y prácticas que favorezcan la reconfiguración de la propia identidad genérica, que se reflejen en la mejora de sus condiciones de vida cotidiana. Se trata de una especie de ruptura identificatoria en el sentido que explica Burín (2000), lo que lleva a la búsqueda de otros elementos identitarios o a lo que Berger y Luckmann (2005) denominan "transformación de uno".

También hay que tener en cuenta que aun dentro de un proceso de juicio crítico existen elementos de la memoria que difícilmente accederán a la conciencia, además de que el exceso de memoria hace perder la capacidad de construir y vivir creativamente el presente y proyectar el futuro (De Zan, 2008). Sin embargo, el olvido puede responder a dispositivos socioculturales para naturalizar las prácticas de género y favorecer la reproducción de las desigualdades, impidiendo la búsqueda de cambios en las relaciones de género. Las experiencias que contradicen lo que se muestra como natural y dado tienden a ser minimizadas y en otros casos olvidadas, lo que facilita que se mantengan relaciones violentas con la pareja y con la madre, principalmente.

En este sentido, todo el proceso de reflexión, análisis y crítica - juicio crítico- a la que varones y mujeres sometemos la identidad propia de género sólo es posible a posteriori: el pasado recuperado por la memoria. No obstante, el proceso de resignificación y transformación puede darse de manera simultánea, siempre que pasado y presente se encuentren en diálogo constante.

\section{Para finalizar}

Autoras como Reguillo (2000) ven en la vida cotidiana el lugar estratégico para observar el cambio social.
Ubicar la capacidad de agencia de varones y mujeres en el contexto de la vida cotidiana ha permitido identificar el papel del lenguaje y de la memoria como dos procesos cognoscitivos que intervienen en la búsqueda de cambios de sentidos y significados. En ambos procesos, el alter significativo es indispensable en la reconfiguración de la identidad de género.

En el proceso de cambio social es fundamental el papel de la memoria, cuyos marcos sociales son el tiempo y el espacio, y se hace posible por el lenguaje. La memoria permite la reconfiguración de las identidades de género y contribuye a crear un espacio de posibilidad para construir otros sentidos y dar nuevos significados a la existencia, una existencia que transcurre como parte del acontecer cotidiano. La búsqueda reflexiva de cambios en las relaciones inter e intragénero no garantiza que éstos ocurran, pero algunos si comienzan a construirse y cobrar sentido, y en este sentido el diálogo constante entre presente y pasado es fundamental porque permite la comparación necesaria para generar cambios.

Algunos elementos de la identidad de género se alejan o se acercan de las normatividades de género en la misma persona, puesto que la identidad presenta lo que en algún momento he denominado núcleos duros, como la maternidad en las mujeres o la proveeduría y protección en los varones entrevistados, independientemente del trabajo formal o de la participación económica de la esposa. En otros casos se identifica mayor flexibilidad, como en el aumento del interés de las mujeres por tener participación económica formal y desarrollarse laboral y profesionalmente, y del interés de los varones por incorporarse a más actividades domésticas y de cuidado de los hijos e hijas o por modificar la relación con la pareja - autoridad conyugal- - Esta flexibilidad también se observa en cambios en el tiempo personal —reconocimiento y búsqueda del mismo- o en el cuestionamiento del significado de la unión religiosa.

En este documento he querido apuntalar algunos planteamientos teóricos en diálogo con datos empíricos en relación con el papel de la memoria y el lenguaje considerando el uso/ocupación del tiempo/espacio en la reconfiguración de las identidades de género. El tema 
tiene una complejidad que tendría que ser estudiada más a fondo.

\section{Notas}

${ }^{1}$ En el período comprendido entre 1930 y 1970 el crecimiento poblacional mantuvo un ritmo moderado: de contar con 23054 habitantes en 1950, se pasó a 27 198 en 1960 y ascendió a 32833 habitantes en 1970 (Vásquez, 2007). A partir de 1970 cambió la situación porque el crecimiento se aceleró radicalmente: de 60550 habitantes en 1980, se pasó a 89335 en 1990, a 132421 en 2000 y, en 2010, ya contaba con 185917 habitantes (INEGI, 2005 y 2010).

${ }^{2}$ La crisis del campo que se vive en Chiapas desde finales de la década de los ochenta produjo cambios significativos en la política agraria y agropecuaria. La entrada en vigor del Tratado de Libre Comercio de América del Norte y el levantamiento armado del EZLN en 1994 detonaron una serie de conflictos entre campesinos y propietarios rurales; aunado a ello, la devaluación del peso mexicano en el mismo año, junto con la falta de opciones de empleo fuera del sector primario, las actividades terciarias - comercio y servicios- empezaron a crecer de manera acelerada (Villafuerte y García, 2006).

${ }^{3}$ La tasa de fecundidad ha disminuido a nivel nacional. En el período de 1976 a 2010 se observa una disminución gradual en el promedio de hijos por mujer de 15 a 49 años de edad: en 1976 la tasa de fecundidad era de 5.7 y en 2010 ésta disminuyó a 2.1, tasa que se ha mantenido desde 2007. No obstante, para el periodo 2000-2010 Chiapas, junto con Guerrero, fueron los dos estados con mayor tasa global de fecundidad (2.3) con relación a otros estados de la República, como es el caso del Distrito Federal, que presenta una tasa de 1.7, lo que lo ubica con la tasa más baja a nivel nacional (INEGI, 2010). En estos datos se deben considerar diferencias en el promedio de hijos por mujer en edad reproductiva de zonas rurales y urbanas. En el caso de San Cristóbal, su tasa global de fecundidad (TGF) para el año 2000 fue de 3.13 hijos por mujer en edad reproductiva, la cual es menor a la registrada en la región (4.45) y el estado (3.47).
${ }^{4}$ La ocupación de los varones entrevistados son: profesor, arquitecto y contador público; y la de las mujeres entrevistadas: maestra, ama de casa/estilista, ama de casa (2), psicóloga y empleada,

5 Los ejes temáticos tratados en las entrevistas se corresponden con las categorías de análisis abordadas en el estudio: división sexual del trabajo, uso/ocupación del tiempo/espacio, ejercicio de la paternidad y la maternidad, sexualidad, acceso a recursos -económicos, materiales y escolares/ oficios-, toma de decisiones, relaciones de poder y malestar.

${ }^{6} \mathrm{La}$ asistencia escolar de la población joven se ha incrementado en los últimos veinte años, al pasar de $21.6 \%$ en 1990 a $34.1 \%$ en 2010 . Este último dato indica que uno de cada tres chiapanecos asiste a la escuela. Asimismo, la asistencia escolar por sexo registra una tendencia a la alza: en los varones pasa del 25\% en 1990, al 34.1\% en 2010 —se incrementa 11.5 puntos porcentuales-, y en las mujeres de 18.4\% en 1990 al 31.8\% en 2010 -más de 13 puntos porcentuales-. No obstante este incremento, hay que señalar que la brecha entre ambos sexos sigue favoreciendo a los varones, ya que la asistencia de éstos con respecto a ellas es mayor en alrededor de cinco puntos porcentuales (INEGI, 1990 y 2010).

${ }^{7}$ De acuerdo con los datos de la Encuesta Nacional de Ocupación y Empleo, en Chiapas se ha modificado la estructura ocupacional: de ser un estado agrícola, actualmente la población económicamente activa (PEA) se concentra en el sector terciario dedicado al comercio y los servicios con el $42.9 \%$; en este sector se ubica el 50.9\% de la PEA femenina, en contraste con el 6.9\% del sector primario (INEGI, ENOE tercer trimestre 2011).

${ }^{8}$ Información obtenida de los relatos de vida y entrevistas realizadas a mujeres de San Cristóbal de Las Casas en el transcurso del trabajo de campo 2010-2013.

${ }^{9}$ Este comentario lo realizó cuando refería lo que esperaba de su matrimonio y la realidad a la que se enfrentó cuando se casó. En su testimonio, además, repitió las palabras que su esposo le decía respecto al arreglo de la casa cuando ella estaba de vacaciones. 
10 Los conceptos de tipificación y habituación son retomados de las explicaciones que Berger y Luckmann (2005) realizan para analizar el origen de la institucionalización. La tipificación surge de la habituación de un acto que, al repetirse con frecuencia, crea una pauta de posibilidades para que pueda reproducirse e institucionalizarse. De esta manera, las pautas definidas de antemano controlan el comportamiento humano al establecer una dirección determinada, en oposición a las muchas otras que podrían darse en el plano teórico. El carácter sancionador de las instituciones es lo que permite que perduren en el tiempo.

${ }^{11}$ Características y actividades consideradas propias de varones y mujeres, construidas de manera diferencial de acuerdo con el género y expresadas en un modelo hegemónico de feminidad y masculinidad que no descarta la existencia de modelos alternativos.

${ }_{12}$ Pepe tenía 14 años cuando asesinaron a su hermano mayor. Ante dicha tragedia, su familia — madre y tíastendía a llamarlo como su hermano muerto y esperaba de él un comportamiento similar, situación que enojó durante muchos años a Pepe, lo cual manifestó haciendo lo contrario de lo que su familia esperaba. Posteriormente se reconcilió consigo mismo y reconoció que se parecía a su hermano.

13 "El éxito espectacular de la colonización española con las etnias indias se ha visto desviado por el uso que se hacía de ella: sumisos, incluso aquiescentes, a menudo estos indios utilizaban las leyes, las prácticas o las representaciones que les eran impuestas por la fuerza o por la seducción con fines diversos a los buscados por los conquistadores; hacían algo diferente con ellas; las subvertían desde dentro; no al rechazarlas o al transformarlas (eso también acontecía), sino mediante cien maneras de emplearlas al servicio de reglas, costumbres o convicciones ajenas a la colonización de la que no podían huir. Permanecían diferentes, en el interior del sistema que asimilaban y que los asimilaba exteriormente. Lo desviaron sin abandonarlo. Los procedimientos de consumo mantenían su diferencia en el espacio mismo que organizaba el ocupante" (De Certeau, 2000: 38).
${ }^{14}$ Término utilizado por Dubar al referirse a la identidad como "resultado de la diferenciación de alguien con relación a los otros y de la generalización que busca definir el nexo común a una serie de elementos diferentes de otros. Operaciones que están en el origen de la paradoja de la identidad: lo que hay de único es lo que hay de compartido" (2002: 11).

\section{Referencias bibliográficas}

Alcoff, Linda (1989). "Feminismo cultural versus posestructuralismo: la crisis de la identidad en la teoría feminista". En Feminaria, año 1l, núm. 4, noviembre, pp. 1-26. Buenos Aires.

Berger, Peter y Thomas Luckman (2005). La construcción social de la realidad. Madrid: Amorrortu.

Burín, Mabel (1990). El malestar de las mujeres. La tranquilidad recetada. México: Paidós.

Cancino, Leobardo (2007). "Recordar juntos, construir juntos”. En D. Camacho, A. Lomelí y P. Hernández (coords.). La ciudad de San Cristóbal de Las Casas, a sus 476 años: una mirada desde las ciencias sociales. México: Gobierno del Estado de Chiapas, Consejo Estatal para las Culturas y las Artes de Chiapas, pp. 21-26.

Cazés, Daniel (2006). "El tiempo en masculino". En G. Careaga y S. Cruz, Debates sobre masculinidades. Poder, desarrollo, políticas públicas y ciudadanía. México: PUEGUNAM, pp. 67-88.

CEPAL (1993). "Hacia un perfil de la familia actual en Latinoamérica y el Caribe". En Cambios en el perfil de las familias: la experiencia regional. Santiago de Chile: CEPAL.

DeCerteau, Michel(2000). La invencióndelocotidiano.IArtes de hacer, vol. 2. México: Universidad Iberoamericana, Instituto Tecnológico de Estudios Superiores de Occidente.

De Zan, Julio (2008). "Memoria e identidad". En TÓPICOS, Revista de Filosofía de Santa Fe, núm. 16, pp. 41-67. Argentina.

Dubar, Claude (2002). La crisis de las identidades. La interpretación de una mutación. Barcelona: Bellaterra.

Echarri, Carlos Javier (2010). "Hogares y familias en México: una visión sociodemográfica”. En S. Lerner y L. Melgar 
(coord.). Familias en el siglo XXI: realidades diversas y políticas públicas. México: PUEG-UNAM, pp. 73-113.

Esteinou, Rosario (2004). "El surgimiento de la familia nuclear en México". En Estudios de Historia Novohispana, núm. 31, julio-diciembre, pp. 99-136.

Fuller, Norma (1997). "Fronteras y retos: varones de clase media del Perú”. En Teresa Valdés y José Olavarría (eds.). Masculinidad/es. Santiago, Chile: Isis Internacional, FLACSO, pp. 139-152.

Garza, Ana María y Sonia Toledo (2004). "Mujeres, agrarismo y militancia. Chiapas en la década de los ochenta". En Maya Lorena Pérez Ruiz (coord.), Tejiendo historias. Tierra, género y poder en Chiapas. México: INAH, pp. 191-218.

Giménez Montiel, Gilberto (2005), "Teoría y análisis de la cultura. México: CONACULTA, pp.18-44.

Halbwachs, Maurice (1950). La Mèmoire Collective. París: PUF.

INEGI (2000). XII Censo General de Población y Vivienda 2000. Aguascalientes, México: INEGI.

INEGI (2010). Censo de Población y Vivienda 2010. Aguascalientes, México: INEGI.

INEGI-STPS (2010). Encuesta Nacional de Ocupación y Empleo, 2009. Segundo trimestre. Base de datos. En Hombres y Mujeres en México, 2010. Aguascalientes, México: INEGI.

Íniguez, Lupicinio (2001). "Identidad: de lo personal a los social. Un recorrido conceptual”. En E. Crespo (ed.). La constitución social de la subjetividad. Madrid: Catarata, pp.: 209-225. Disponible en: http://antalya.uab.es/ liniguez/Materiales/identidad.pdf.

Jelin, Elizabeth (2002). Los trabajos de la memoria. España: Siglo XXI.

Lindón, Alicia (2000). "La espacialidad como fuente de innovaciones de la vida cotidiana. Hacia modos de vida cuasi fijos en el espacio". En Alicia Lindón (coord.), La vida cotidiana y su espacio-temporalidad. México: Anthropos, pp. 187-209.
Mendoza, Jorge (2005). "Exordio a la memoria colectiva y el olvido social”. En Athenea Digital, núm. 8, otoño, pp. 1-26.

Olivera Bustamante, Mercedes (2009). “Las organizaciones de mujeres de Chiapas: mosaico de luces y esperanzas". En Las luchas por los derechos de las mujeres en Chiapas: un directorio de organizaciones sociales que trabajan a favor de las chiapanecas. México: Red Internacional de Mujeres Lilla. Disponible en: http://redlilla.files. wordpress.com/2009/09/red-lilla-directorio-color-v2introduccion. pdf.

Reguillo, Rossana (2000). "La clandestina centralidad de la vida cotidiana”. En Alicia Lindón (coord.), La vida cotidiana y su espacio-temporalidad. México: Anthropos, pp. 77-93.

Ribeiro, Gerardo (1989). "Lenguaje y discurso jurídico". En R. Alexy (coord.), Teoría de la argumentación jurídica. España: Centro de Estudios Constitucionales.

Riquer, Florinda (1997). "La identidad femenina en la frontera entre la conciencia y la interacción social". En María Luisa Tarrés (comp.), La voluntad de ser. Mujeres de los noventas. México: El Colegio de México, pp. 5l-64.

Robledo, Gabriela (2010). "Vivir en la ciudad. La migración rural urbana en el altiplano chiapaneco", Migración. México: CIESAS, pp.109-142.

Taracena Arriola, Arturo (2012). "Historia, memoria, olvido y espacio". Texto basado en la conferencia magistral presentada en el XI Congreso Centroamericano de Historia, del 6 al 10 de agosto de 2012 en la Universidad de Ciencias y Artes de Chiapas, San Cristóbal de Las Casas. Disponible en: http://istmo.denison.edu/ n25-26/articulos/08_taracena_arturo_form.pdf. Villafuerte Solís, Daniel y María del Carmen García Aguilar (2006). "Crisis y migraciones en Chiapas". En Migración y Desarrollo, vol. 6, pp. 102-130. 